\title{
Inorganic salts interact with oxalic acid in submicron particles to form material with low hygroscopicity and volatility
}

\author{
G. Drozd $^{1}$, J. Woo ${ }^{1}$, S. A. K. Häkkinen ${ }^{1,2}$, A. Nenes ${ }^{3}$, and V. F. McNeill ${ }^{1}$ \\ ${ }^{1}$ Department of Chemical Engineering, Columbia University, New York, NY 10027, USA \\ ${ }^{2}$ Department of Physics, University of Helsinki, 00014, Helsinki, Finland \\ ${ }^{3}$ Schools of Earth \& Atmospheric Sciences and Chemical \& Biomolecular Engineering, Georgia Institute of Technology, \\ Atlanta, GA 30332, USA
}

Correspondence to: V. F. McNeill (vfm2103@ columbia.edu)

Received: 30 September 2013 - Published in Atmos. Chem. Phys. Discuss.: 22 November 2013

Revised: 7 March 2014 - Accepted: 28 March 2014 - Published: 27 May 2014

\begin{abstract}
Volatility and hygroscopicity are two key properties of organic aerosol components, and both are strongly related to chemical identity. While the hygroscopicities of pure salts, di-carboxylic acids (DCA), and DCA salts are known, the hygroscopicity of internal mixtures of these components, as they are typically found in the atmosphere, has not been fully characterized. Here we show that inorganicorganic component interactions typically not considered in atmospheric models can lead to very strongly bound metalorganic complexes and greatly affect aerosol volatility and hygroscopicity; in particular, the bi-dentate binding of DCA to soluble inorganic ions. We have studied the volatility of pure, dry organic salt particles and the hygroscopicity of internal mixtures of oxalic acid (OxA, the dominant DCA in the atmosphere) and a number of salts, both mono- and divalent. The formation of very low volatility organic salts was confirmed, with minimal evaporation of oxalate salt particles below $75^{\circ} \mathrm{C}$. Dramatic increases in the cloud condensation nuclei $(\mathrm{CCN})$ activation diameter for particles with di-valent salts (e.g., $\mathrm{CaCl}_{2}$ ) and relatively small particle volume fractions of OxA indicate that standard volume additivity rules for hygroscopicity do not apply. Thus small organic compounds with high $\mathrm{O}: \mathrm{C}$ ratios are capable of forming lowvolatility and very low hygroscopicity particles. Given current knowledge of the formation mechanisms of OxA and $\mathrm{M}-\mathrm{Ox}$ salts, surface enrichment of insoluble $\mathrm{M}-\mathrm{Ox}$ salts is expected. The resulting formation of an insoluble coating of metal-oxalate salts can explain low-particle hygroscopicities. The formation of particles with a hard coating could offer an
\end{abstract}

alternative explanation for observations of glass-like particles without the need for a phase transition.

\section{Introduction}

The ubiquity of di-carboxylic acids (DCA) is well documented both in urban and rural terrestrial aerosol and marine aerosol (Warneck, 2003; Wang et al., 2006; Wang and Kawamura, 2006; Tan et al., 2010; Sempéré and Kawamura, 1996; Pavuluri et al., 2010; Ma et al., 2013; Kundu et al., 2010; Kawamura et al., 1996, 2007; Gierlus et al., 2012; Altieri et al., 2008). A recent study of marine aerosol from around the globe found that DCA contribute on average $\sim 15 \%$ to total marine organic aerosol (OA) mass (Fu et al., 2013; Myriokefalitakis et al., 2011). DCA are commonly associated with aqueous processing of water soluble organics (Ervens et al., 2011; Tan et al., 2010) and hence readily affect aerosol-water interactions. Oxalic acid (OxA) is typically the dominant DCA found in aerosol (Neusüss et al., 2000). It was shown to contribute more than $50 \%$ on average of the total mass of marine DCA, and mineral dust is often enriched in OxA (Sullivan et al., 2009; Fu et al., 2013). High oxidation states and the ability to strongly interact with inorganic compounds (especially crustal/marine salts) make the effects of DCA on aerosol composition and physical properties unique and complex. However, the impact of such interactions on particles' properties are not well understood. In this study we focus on DCA interactions with inorganic salts and their impacts on hygroscopicity and volatility. 
Reactions of OxA with deliquescent salts of mono-valent and di-valent cations represent an important class of DCA -salt interactions in atmospheric aerosols. Mono-valent cations are typically a major inorganic constituent of atmospheric aerosol, in particular $\mathrm{Na}^{+}$(e.g., from $\mathrm{NaCl}$ ) and $\left(\mathrm{NH}_{4}\right)^{+}$(e.g from $\left.\left(\mathrm{NH}_{4}\right)_{2} \mathrm{SO}_{4}\right)$. Di-valent cations may be a significant component of sea salt (e.g., $\mathrm{MgCl}_{2}, \mathrm{CaCl}_{2}$ ) and mineral dust (e.g., $\mathrm{CaCO}_{3}$ ). Seawater aerosol may typically contain $10 \mathrm{wt} \%$ di-valent salts (Pratt et al., 2010), while dust aerosol is more variable with at least $5-10 \mathrm{wt} \% \mathrm{CaCO}_{3}$, or more (Kumar et al., 2009; Sullivan et al., 2009). OxA may react with both mono- and di-valent cations to form lowvolatility complexes, but the metal valency will largely determine OxA / metal effects on hygroscopicity. While monovalent ions $\left(\mathrm{Na}^{+}, \mathrm{NH}_{4}^{+}\right.$, etc.) react with DCA to form moderately soluble/hygroscopic organic salts, di-valent cations $\left(\mathrm{Ca}^{2+}, \mathrm{Mg}^{2+}\right.$, etc. $)$ react with DCA to form very low solubility, low-volatility compounds that exhibit low hygroscopicity.

Studies of both pure components of salt/DCA particles (e.g., $\mathrm{CaCO}_{3}, \mathrm{H}_{2} \mathrm{C}_{2} \mathrm{O}_{4}, \mathrm{CaC}_{2} \mathrm{O}_{4}$ ) as well as external mixtures of particles of these pure components indicate that dust or salt particles that include DCA may show reduced hygroscopicities due to formation of low-solubility compounds (Sullivan et al., 2009; Ma et al., 2010, 2013; Ma and He, 2012). While pure particles of DCA and salts and their external mixtures shed insight on the probable behavior of particles containing these compounds, internal mixtures of these components (single particles containing DCA, their organic salts, and inorganic salts) will also be important in the atmosphere. Several processes may lead to such internally mixed particles, with initial water content largely determining the route to DCA formation and thus probable particle morphology. Gas-phase water-soluble organic compounds (WSOC), such as glyoxal and glutaric acid, will partition to aerosol water. They may then be oxidized in the particle aqueous phase to produce OxA (Warneck, 2003), which can then react with mineral ions in the particle to produce insoluble material (e.g., calcium oxalate), reducing particle hygroscopicity. OxA has also been found to be significant in particles dominated by non-hygroscopic material (e.g., mineral dust) (Sullivan and Prather, 2007). For these particles, solubilizing reactions, such as uptake of nitric acid, may occur at the particle surface, and subsequent water exposure creates conditions ripe for reaction between OxA and di-valent cations (Laskin et al., 2012). Surface reactions between oxalic acid and metal chlorides can produce highly volatile hydrochloric acid, and evaporation of $\mathrm{HCl}$ will drive the in-particle equilibrium towards formation of the insoluble M-Ox complex (Laskin et al., 2005). Loss of volatile products occurs at the particle surface, leading to enrichment of the remaining lower volatility material at the particle surface. When present at the particle surface, only small amounts of low-solubility material are required to strongly affect particle hygroscopicity (Schwier et al., 2011). A recent study has directly shown surface enrichment of di-valent material in naturally occurring sea-salt aerosol (Ault et al., 2013). Finally, separate particle populations containing DCA and di-valent metals in an external mixture may combine via coagulation to form internal mixtures (Ma and $\mathrm{He}, 2012$ ). Thus there are multiple formation pathways for particles consisting of soluble di/poly-valent salts and DCA, and the hygroscopicity of these particles will depend on both the amount of DCA - - metal complexation and the final particle morphology (i.e., potential surface enrichment of insoluble complexes).

Accurately describing gas-particle partitioning and predicting atmospheric aerosol loading requires knowledge of how low-volatility salts contribute to particle growth and alter the overall volatility of aerosol particles (Lee et al., 2012). Low-volatility atmospheric species have special importance since they participate in aerosol particle growth, in particular the growth of very small, freshly nucleated particles (Kulmala et al., 2004; Pierce et al., 2011; Riipinen et al., 2012). Aerosol particles smaller than $50 \mathrm{~nm}$ in diameter are expected to contain compounds with equilibrium vapor pressures as low as $10^{-8}-10^{-7} \mathrm{~Pa}$ (Pierce et al., 2011). Such low vapor pressures can be achieved by organic salt formation via acid-base reactions (Riipinen et al., 2012; Barsanti et al., 2009). For example, OxA has a high vapor pressure $\left(\sim 10^{-2} \mathrm{~Pa}\right)$, but the majority of atmospheric OxA resides in the particle phase due to oxalate formation (Ervens et al., 2011 and references therein). The formation of organic salts is also a reactive sink of particle-phase organics, enhancing gas phase uptake (Pierce et al., 2011). Recently, the formation of low-volatility organic salts has been observed under various atmospheric conditions in reactions of organic acids with mineral salts (Laskin et al., 2012), ammonium (Martinelango et al., 2007; Dinar et al., 2008; Ortiz-Montalvo et al., 2012) and amines (Sorooshian et al., 2008; Smith et al., 2010).

Recent field studies, performed both in urban and remote environments, have pointed out the existence of very low-volatility (non-volatile even at temperatures as high as $280^{\circ} \mathrm{C}$ ) organics in submicron aerosol particles (Wehner et al., 2002; Ehn et al., 2007; Backman et al., 2010; Häkkinen et al., 2012). Häkkinen et al. (2012) observed a positive correlation between low-volatile aerosol material, atmospheric particulate organics, and organic nitrates at a boreal forest site in central Finland, owing to the presence of lowvolatility organonitrates or organic salts. Since the contribution of sea salt (or other mineral salts) in submicron particles at continental forest sites far from the sea is minor (Saarikoski et al., 2005), ammonium or aminium salts are likely main contributors to the growth of aerosol particles, even at sub-20 nm sizes (Barsanti et al., 2009; Smith et al., 2010). However, at marine sites or other mineral-rich areas the contribution of organic salts from mineral-salt-organicacid reactions may have a significant effect on aerosol chemical properties and further cloud processing (Furukawa and Takahashi, 2011; Laskin et al., 2012; Rinaldi et al., 2011; 
Sorooshian et al., 2013). These results emphasize the fact that atmospheric species, both organic and inorganic, can undergo drastic changes when they react with each other and these changes can alter the chemical and physical properties of particles.

This study addresses the major effects of DCA-cation interactions on two key aerosol properties, hygroscopicity and volatility. Towards understanding these effects, internally mixed particles were created by exposing several metalchloride salts to gas-phase OxA. The hygroscopicity and volatility of the resulting particles was then studied. From the results we assess the applicability of the standard volume additivity rules for hygroscopicity ( $\kappa$-Köhler theory) and aerosol partitioning of organics that may bind to metals in terms of surface processes and unaccounted inorganicorganic interactions.

\section{Methods}

\subsection{Experimental}

\subsubsection{Aerosol generation}

For hygroscopicity measurements, salt-oxalate aerosols were generated by deposition of gas-phase oxalic acid onto dry, inorganic aerosol. Salt particles were generated from aqueous solutions of $\mathrm{CaCl} 2.6 \mathrm{H} 2 \mathrm{O}$ (Sigma Aldrich $98 \%$ ), $\mathrm{MgCl} 2.6 \mathrm{H} 2 \mathrm{O}$ (Fisher Scientific $99 \%$ ), $\mathrm{ZnCl} 2$ (Sigma Aldrich $98 \%$ ), $\mathrm{NaCl}$ (Fisher Scientific 99\%), and $\mathrm{Na} 2 \mathrm{C} 2 \mathrm{O} 4$ (Fisher Scientific 99.5\%). In addition to solutions of each individual salt, three mixtures were used: $8: 1$ and $1: 1$, by mass, $\mathrm{NaCl} / \mathrm{MgCl}_{2}$, and Instant Ocean. Instant Ocean is a commercially available mixture of salts used as a proxy for sea salt, with the $\mathrm{NaCl}$ and $\mathrm{MgCl}_{2}$ as the main components. The total salt concentration for all solutions was $0.2 \mathrm{M}$.

Salt solutions were atomized (TSI Model 3076), then diluted with dry nitrogen to low ( $<10 \% \mathrm{RH})$ humidity, to induce efflorescence. Aerosols were then introduced to a glass tube coated with a layer of solid oxalic acid, which was heated to a constant temperature. Heating was provided by resistive heating tape with a set applied voltage. The aerosol mixture was then diluted using humidified nitrogen, such that the desired RH was attained. After OxA deposition, the particles were re-humidified to $\sim 10 \% \mathrm{RH}$ above deliquescence for the di-valent salts, which under these conditions should always remain as hydrates (e.g., $\mathrm{CaCl}_{2} \cdot 2 \mathrm{H}_{2} \mathrm{O}$ ). Rehumidification will hydrate particle surfaces and may create aqueous droplets; causing mixing to facilitate surface chemistry prior to measurement. Just prior to entering the DMA, the particles were passed through a diffusion drier charged with silica bead desiccant. The air stream exiting the drier was always less than $10 \% \mathrm{RH}$ (measured via $\mathrm{RH}$ probe; Vaisala), leaving minimal residual particle water. Separate test experiments with a second drier to reach less than $2 \%$ RH did not show significantly different results.

Aerosol size distributions were measured via SMPS (TSI Model 3775). Upshifting of the dry aerosol mean diameter was used to estimate the amount of adsorbed oxalic acid onto aerosols after being exposed to the heated tube. cloud condensation nuclei $(\mathrm{CCN})$ activity for all particles was measured using a Constant flow rate streamwise thermal gradient CCN counter (CFSTGC, Droplet Measurement Technologies) (Lance et al., 2006; Roberts and Nenes, 2005).

For volatility studies, $\mathrm{Na}_{2} \mathrm{Ox}\left(\mathrm{Na}_{2} \mathrm{C}_{2} \mathrm{O}_{4}\right)$ and oxalic acid $\left(\mathrm{C}_{2} \mathrm{H}_{2} \mathrm{O}_{4}\right)$ particles were generated slightly differently than the $\mathrm{CaOx}$ particles. $\mathrm{Na}_{2} \mathrm{Ox}$ aerosol was produced by atomizing a solution of sodium oxalate (Fisher Scientific, $>99.5 \%$ purity) and deionized water and OxA aerosol by atomizing a solution of oxalic acid (oxalic acid di-hydrate, Fisher Scientific, $>99.5 \%$ purity) and deionized water. These particles were passed through a diffusion drier charged with silica bead desiccant prior to heating. The mean number concentrations and geometric mean diameters of the generated particles (oxalic acid, $\mathrm{Na}_{2} \mathrm{Ox}$ and $\mathrm{CaOx}$ ) measured with a SMPS (during oxalic acid and $\mathrm{Na}_{2} \mathrm{Ox}$ experiments SMPS by TSI, during $\mathrm{CaOx}$ experiment SMPS by Grimm Technologies) before introducing the aerosol to the temperature programmed desorption aerosol-chemical ionization mass spectrometer (TPD) aerosol-CIMS are presented in Table 1.

\subsubsection{Temperature programmed desorption aerosol-CIMS}

TPD aerosol-CIMS (temperature programmed desorption aerosol-chemical ionization mass spectrometer) consists of a quadrupole mass spectrometer coupled with a heated volatilization flow tube inlet (McNeill et al., 2007). Compared to more traditional instruments which measure aerosol volatility by detecting change in aerosol particle diameter upon heating (Philippin et al., 2004; Wehner et al., 2005; Ehn et al., 2007), TPD aerosol-CIMS detects changes in volatilized aerosol organics in the gas phase via CIMS. In the heating region, the aerosol stream flows through a PFA tube (OD $1.27 \mathrm{~cm}$, length $23 \mathrm{~cm}$ ) wrapped with a heating tape (VWR). Diluted aerosol flow of $1.8 \mathrm{~L} \mathrm{~min}^{-1}$ from the total flow of 5-6 $\mathrm{L} \mathrm{min}^{-1}$ enters the heating tube giving the aerosol a residence time of less than a second in the tube. The temperature in the heated region is controlled by a temperature controller (Staco Energy Products Co.) and monitored using a thermocouple. The aerosol (gas-particle mixture) is then introduced to an ionizer where the gas-phase analyte molecules (i.e., oxalic acid) react with $\mathrm{I}^{-}$reagent ion to form clusters (see details in Sareen et al., 2010). Ion clusters are guided from atmospheric pressure to ultrahigh vacuum $\left(\sim 10^{-8}\right.$ Torr $)$ using differential pumping and the masses (mass-to-charge ratio, $\mathrm{m} / \mathrm{z}$ ) of these clusters are determined using a quadrupole mass spectrometer. Aerosol evaporation is observed as an increase in signal when the 
Table 1. Physical properties of the generated particle size distribution - mean geometric size and mean concentrations of the particles during the TPD aerosol-CIMS experiments are presented. Onset temperatures for evaporation and $\Delta H_{\mathrm{vap}}$ of oxalate at different temperature ranges; the number of data points used in the linear fits are in parentheses. Experiments were performed using oxalic acid aerosol, sodium oxalate $\mathrm{Na}_{2} \mathrm{Ox}$ and calcium oxalate $(\mathrm{CaOx})$.

\begin{tabular}{cccccc}
\hline & \multicolumn{2}{c}{$\begin{array}{c}\text { Physical properties } \\
\text { measured with SMPS }\end{array}$} & \multicolumn{2}{c}{$\begin{array}{c}\text { Evaporation properties measured } \\
\text { with TPD aerosol-CIMS }\end{array}$} \\
\cline { 2 - 6 } Aerosol & $\begin{array}{c}\text { Mean } \\
\text { geometric } \\
\text { diameter } \\
(\mathrm{nm})\end{array}$ & $\begin{array}{c}\text { Mean total } \\
\text { particle number } \\
\text { concentration } \\
\left(10^{4} \mathrm{~cm}^{-3}\right)\end{array}$ & $\begin{array}{c}\text { Onset } T \\
\left({ }^{\circ} \mathrm{C}\right)\end{array}$ & $\begin{array}{c}\Delta H_{\text {vap }} \\
\left(<75^{\circ} \mathrm{C}\right)\end{array}$ & $\begin{array}{c}\Delta H_{\text {vap }} \\
\left(>75^{\circ} \mathrm{C}\right)\end{array}$ \\
\hline $\begin{array}{c}\text { Oxalic acid } \\
\mathrm{Na}_{2} \mathrm{Ox}\end{array}$ & 41 & 1.1 & 25 & $85 \pm 12(3)$ & - \\
$\mathrm{CaOx}$ & 76 & 7.4 & 95 & - & $60 \pm 8(4)$ \\
& 100 & 39.1 & 115 & - & $87 \pm 36(3)$ \\
\hline
\end{tabular}

temperature in the vaporization flow tube (VFT) is increased. In this study mean temperatures at the VFT centerline were used in the data analysis. Linear correspondence between the temperature of the flow tube external wall and the actual VFT temperature was determined in the range of $25-114^{\circ} \mathrm{C}$. See Sareen et al. (2010) for a more detailed description of the instrument used see Sareen et al. (2010).

When investigating the volatility of oxalate salts $\left(\mathrm{Na}_{2} \mathrm{Ox}\right.$, $\mathrm{CaOx}$ ), the heating temperature was increased step wise using mean inlet temperatures from $25^{\circ} \mathrm{C}$ to $180^{\circ} \mathrm{C}$ (altogether at 8-9 temperatures). Signal response for a given molecular cluster to temperature change was rapid. It took around 30 to $90 \mathrm{~min}$ to stabilize per temperature setting. The studied oxalate salts were observed as clusters of oxalic acid and $\mathrm{I}^{-}$in the TPD aerosol-CIMS. Detecting organic salts in the CIMS as their corresponding acids has been observed before (McNeill et al., 2007). It is known that gas-phase oxalic acid can thermally decompose at sufficiently high temperatures $\left(\sim 100^{\circ} \mathrm{C}\right)$ forming formic acid and $\mathrm{CO}_{2}$ (Higgins et al., 1997). This was taken into account when performing oxalate salt experiments; instead of tracing only oxalic acid $\left(217 \pm 0.5 \mathrm{amu}, \mathrm{I}^{-} \cdot \mathrm{C}_{2} \mathrm{H}_{2} \mathrm{O}_{4}\right)$ also formic acid $\left(173 \pm 0.5 \mathrm{amu}, \mathrm{I}^{-} \cdot \mathrm{CH}_{2} \mathrm{O}_{2}\right)$ was traced and the total oxalate signal was taken as the sum of these two signals (e.g., Fig. 4). The observed oxalate signal was $1-10 \%$ of the mass spectrometer signal of the reagent ion, which was $\sim 100 \mathrm{kcps}$.

The calibration of the TPD aerosol-CIMS was done with pure oxalic acid aerosol observed as a cluster of $\mathrm{I}^{-}$(see the "Enthalpy of vaporization" and "Volatility of oxalate salts" sections for more about the calibration and other data analysis). All of the TPD aerosol-CIMS experiments were performed at relative humidities below $10 \%$ in order to keep the contribution of water negligible (Saleh et al., 2010; Cappa et al., 2007). This was done by drying the particles using silica gel dryer after particle generation. Due to minor contamination inside the ionization regime and/or in the tubing, a constant background of oxalate was always present. Before every experiment the background was determined and removed from the observed oxalate signal in the data analysis.

\subsection{Data analysis/modeling}

\subsubsection{Hygroscopicity and CCN activity}

Hygroscopicities of aerosol mixtures were compared using $\kappa$, a single parameter representation of CCN activity (Petters and Kreidenweis, 2007),

$$
\kappa=\frac{4 A^{3}}{27 D_{\mathrm{d}}^{3} \ln ^{2}\left(1+s_{\mathrm{c}}\right)},
$$

where critical supersaturation, $s_{\mathrm{c}}$, is the supersaturation required for a given particle of dry diameter, $D_{\mathrm{d}}$, to activate. $\mathrm{A}$ is a constant-temperature parameter expressing particle curvature effects on vapor pressure

$A=\frac{4 \sigma_{\mathrm{s} / \mathrm{a}} M_{\mathrm{w}}}{R T \rho_{\mathrm{w}}}$,

where $\sigma_{\mathrm{s} / \mathrm{a}}$ is the solution surface tension at the point of activation, $M_{\mathrm{W}}$ is the molecular mass of water, $R$ is the universal gas constant, $T$ is the solution temperature, and $\rho_{\mathrm{w}}$ is the density of water. The surface tension of water, $0.072 \mathrm{~J} \mathrm{~m}^{-2}$, was used for all $\kappa$ calculations.

For mixtures of soluble component species, $\kappa$ can be approximated as a summation of its volume-fraction-weighted terms (Petters et al., 2007):

$\kappa=\sum_{i} \kappa_{i} \varepsilon_{i}$,

where $\kappa_{i}$ and $\varepsilon_{i}$ are the individual component hygroscopicities and volume fractions, respectively. Using the volume of oxalic deposition onto the inorganic aerosol, and literature and measured values of pure substance hygroscopicities, or $\kappa$ values, (Tables 1 and 2) were calculated taking into account the conversion of oxalic acid and inorganic salts to their respective oxalate salts. The calculated values 
Table 2. $\kappa$ values for mono-valent salts. $\kappa_{\text {intr }}$ calculated using Eq. (5). The densities are from CRC handbook, except for $\mathrm{Na}_{2} \mathrm{Ox}-\left(4-\mathrm{H}_{2} \mathrm{O}\right)$, which was assigned a density of $1.52 \mathrm{~g} \mathrm{~cm}^{-3}$.

\begin{tabular}{ccccc}
\hline Aerosol Species & $\rho\left(\mathrm{g} \mathrm{cm}^{-3}\right)$ & $\kappa_{\text {intr }}$ & $\kappa_{\text {meas }}$ & $\kappa_{\text {lit }}$ \\
\hline$\left(\mathrm{NH}_{4}\right)_{2} \mathrm{SO}_{4}$ & 1.77 & 0.73 & 0.61 & $0.61^{\mathrm{a}}$ \\
$\mathrm{NaCl}$ & 2.16 & 1.34 & 1.05 & $1.28^{\mathrm{a}}$ \\
$\mathrm{Na}_{2} \mathrm{Ox}$ & 2.34 & 0.95 & 0.4 & - \\
$\mathrm{Na}_{2} \mathrm{Ox}-\left(4-\mathrm{H}_{2} \mathrm{O}\right)$ & 1.52 & 0.4 & 0.4 & - \\
$\mathrm{OxA}$ & 1.14 & 0.21 & 1.88 & $0.2-0.5^{\mathrm{a}, \mathrm{b}}$ \\
$\mathrm{OxA}-\left(2-\mathrm{H}_{2} \mathrm{O}\right)$ & 1.65 & 0.71 & 0.21 & $0.2-0.5^{\mathrm{a}, \mathrm{b}}$ \\
\hline
\end{tabular}

a Sullivan (2009).

${ }^{b}$ Petters (2009).

for $\kappa$ reflect a theoretical range of hygroscopicities that can arise from reaction and bulk mixture effects alone. Deviations from this range of values suggests additional compositional effects not accounted for by mixing alone. The CCN activity of the aerosol is defined by the minimum dry diameter, $d_{\mathrm{p} 50}$, at which $50 \%$ of the particles activate at a given $s_{\mathrm{c}}$. $d_{\mathrm{p} 50}$ is determined by fitting a sigmoid curve to the measured ratio of $\mathrm{CCN}$ to $\mathrm{CN}$ concentrations as a function of dry particle diameter, accounting for multiply charged particles as in Moore et al. (2010).

\subsubsection{Enthalpy of vaporization}

The effective enthalpies of vaporization of the aerosol constituents $\left(\Delta H_{\mathrm{vap}}, \mathrm{kJ} \mathrm{mol}^{-1}\right)$ can be determined using TPD aerosol-CIMS, by applying the Clausius-Clapeyron equation as follows:

$\ln \left(\frac{\operatorname{signal}\left(T_{2}\right)}{\operatorname{signal}\left(T_{1}\right)}\right)=-\frac{\Delta H_{\mathrm{vap}}}{R}\left(\frac{1}{T_{2}}-\frac{1}{T_{1}}\right)$,

where $R$ is gas constant, $T$ is mean temperature of the gas in the flow tube and the mean observed signal, $\operatorname{signal}(T)$, is proportional to the effective vapor pressure of the studied aerosol species. $\Delta H_{\mathrm{vap}}$ depends on temperature, however, it can be approximated as a constant in relatively narrow temperature ranges. Hence, Eq. (4) can be considered a linear equation and $\Delta H_{\text {vap }}$ can be determined from the slope of the curve fitted to the experimental data using least-square method that takes into account known covariance. The covariance of each data point (mean signal at temperature $T$ ) was the standard deviation of the aerosol-CIMS signal squared. The curvature (Kelvin) effect on vapor pressure was found to be insignificant in the calculation of $\Delta H_{\mathrm{vap}}$ (Seinfeld and Pandis, 2006). According to calculations $\left(\frac{2 \sigma M}{\rho_{1} r_{\mathrm{p}}}\right.$ vs. $\Delta H_{\mathrm{vap}, \mathrm{CIMS}}$, where $\sigma, M$ and $\rho_{1}$ are surface tension, $72 \mathrm{mN} \mathrm{m}^{-1}$, molar mass, $126.07 \mathrm{~g} \mathrm{~mol}^{-1}$, and liquid density, $1.653 \mathrm{~g} \mathrm{~cm}^{-3}$, respectively) the influence of Kelvin effect on the $\Delta H_{\mathrm{vap}}$ is minor (below $1 \%$ with $r_{\mathrm{p}}$ of $20 \mathrm{~nm}$ ). Equation (4) also assumes compounds do not react during the heating process.

\section{Results and discussion}

CCN activity expressed by $\log -\log$ plots of $d_{\mathrm{p}}$ vs. $s_{\mathrm{c}}$ for sodium-dominated particles are shown in Fig. 2. Pure salt particles are shown in solid curves while salt particles with OxA deposited are shown with dashed curves. For reference, pure sodium oxalate and ammonium sulfate are shown by the thick-dashed red line, and the thick black line, respectively. Following an analysis similar to that of Sullivan et al. (2009), we can calculate intrinsic $\kappa$ values, $\kappa_{\text {intr }}$ (i.e., hygroscopicity if the material is completely soluble), to aid the interpretation of observed hygroscopicites,

$\kappa_{\text {intr }}=\frac{v \rho_{\mathrm{s}} M_{\mathrm{W}}}{\rho_{\mathrm{W}} M_{\mathrm{S}}}$,

where $\rho_{\mathrm{s}}$ is the density and $M_{\mathrm{S}}$ the molecular weight of the material, $\rho_{\mathrm{w}}$ is the density and $M_{\mathrm{w}}$ the molecular weight of water, and $v$ is the number of ions for complete dissociation of the solute. These values are shown in Table 2 for monovalent salts and their hydrates (densities from CRC handbook). While our measurements for the pure mono-valent chloride aerosols (with no oxalate) yield $\kappa$ values that are consistent with previously measured values, measurements for mono-valent salts containing oxalate are similar to those of salt-hydrates, even after drying. This is consistent with the findings of Ma et al. (2013), which suggest the persistence of hydrates under dry conditions, without heating in addition to drying. Addition of oxalate to sodium (mono-valent) dominated salt particles has only a modest effect, due to their high solubility. From the results of Sullivan et al. (2009) large increases in hygroscopicity may result from mixing small amounts of highly soluble material to lower solubility material that has a high intrinsic hygroscopicity. Added water solubilizes the low-solubility core and induces non-linear response in mixing (Nenes et al., 2002, Kokkola et al., 2008). The orange points in Fig. 2 show mixtures of $\mathrm{NaCl}$ with the other main component in sea salt, $\mathrm{MgCl}_{2}$. The two mixtures are $8: 1$ and $1: 1 \mathrm{NaCl} / \mathrm{MgCl}_{2}$, and it is clear that deposition of OxA to particles with greater di-valent salt content creates significantly less hygroscopic particles. The measured hygroscopicities for these mixtures in fact agree well with the calculated $\kappa_{\text {intr }}$, as might be expected for particles with dominant $\left(8: 1 \mathrm{NaCl} / \mathrm{MgCl}_{2}\right)$ and significant $\left(1: 1 \mathrm{NaCl} / \mathrm{MgCl}_{2}\right)$ amounts of highly soluble $\mathrm{NaCl}$.

The CCN measurements for particles dominated by divalent salts, both pure and after OxA deposition, are shown in Fig. 3. In all cases, deposition of OxA incurs a very large decrease in hygroscopicity to the salt particles, as indicated by substantial increases of the critical diameter at a given supersaturation. For the pure di-valent salt particles, our experimental values agree closely with the $\kappa_{\text {intr }}$ for the chloride hydrate salts rather than the pure salts. (Table 3). As for the mono-valent salts, this is reasonable because fully removing water from the deliquesced salt particles can require heating in addition to low humidity (Ma et al., 2013). 


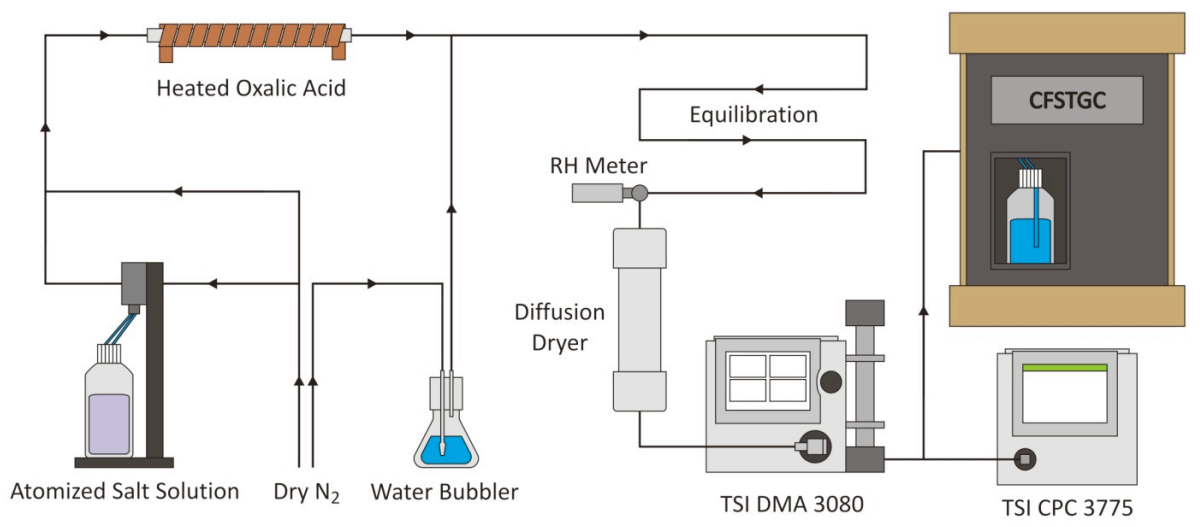

Figure 1. A schematic diagram of the experimental setup for $\mathrm{CCN}$ measurements.

Table 3. Solubilities (sol), intrinsic $\kappa$ values $\left(\kappa_{\text {intr }}\right)$, and measured $\kappa$ values $\left(\kappa_{\text {meas }}\right)$ for di-valent metal salts and their hydrates $(\mathrm{Cl}-\mathrm{Hyd}) . \kappa_{\text {intr }}$ were calculated using Eq. (5) with densities from the CRC handbook.

\begin{tabular}{cccccc}
\hline Aerosol Species & $\rho / \rho_{\text {hydrate }}\left(\mathrm{g} \mathrm{cm}^{-3}\right)$ & $\mathrm{Cl}-\mathrm{sol}\left(\mathrm{g} \mathrm{L}^{-1}\right)$ & $\mathrm{Cl}-\kappa_{\text {intr }}$ & $(\mathrm{Cl}-\mathrm{Hyd})-\kappa_{\text {intr }}$ & $\mathrm{Cl}-\kappa_{\text {meas }}$ \\
\hline $\mathrm{Zn}$ & $2.91: 2.24$ & 4080 & 1.16 & 0.71 & 0.75 \\
$\mathrm{Ca}$ & $2.15: 1.71$ & 813 & 1.05 & 0.68 & 0.64 \\
$\mathrm{Mg}$ & $2.32: 1.57$ & 560 & 1.32 & 0.42 & 0.47 \\
\hline
\end{tabular}

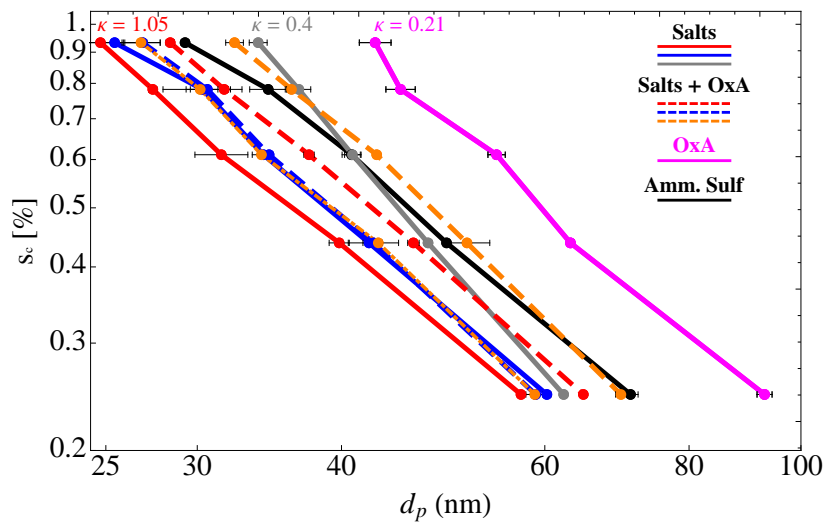

Figure 2. Critical supersaturation, $s_{\mathrm{c}}$, of mono-valent salt particles as a function particle diameter. Results for inorganic salts without OxA deposition are shown by solid lines: $\mathrm{NaCl}$ (red), Instant Ocean (blue), $\mathrm{Na}_{2} \mathrm{Ox}$ (gray). The corresponding salts with OxA deposition are dashed lines with the same color. The orange, thick-dashed and thin-dashed lines are for the $1: 1$ and $8: 1$ mixtures of $\mathrm{NaCl} / \mathrm{MgCl}_{2}$ with OxA deposition, respectively. Pure OxA and ammonium sulfate are shown in solid magenta, and black lines, respectively. $\kappa$ values are shown for $\mathrm{NaCl}$ (red), $\mathrm{Na}_{2} \mathrm{Ox}$ (gray), and OxA (magenta).

The $s_{\mathrm{c}}$ vs. $d_{\mathrm{p}}$ curves for the mixtures of di-valent salts and OxA (Fig. 3) are not linear over the full range of measurements. For example, the $d_{\mathrm{p} 50}$ for $\mathrm{CaCl} 2+\mathrm{OxA}$ at an $s_{\mathrm{c}}$ of 0.4 is roughly $30 \mathrm{~nm}$ below the linear trend of the values at high $s_{\mathrm{c}}$. This dependence on size, and hence surfacearea: / volume ratio, suggests that surface effects are at play.
The process of $\mathrm{CCN}$ activation begins with water adsorption and is then governed by component volume fractions, so the surface-area/volume ratio of the particle, which is size dependent, may be affecting particle hygroscopicities.

Calculating the $\kappa$ values of the final mixtures present after OxA deposition is slightly complicated by the volatility of co-formed $\mathrm{HCl}$ upon reaction of the salt with oxalic acid. As has been shown by Laskin et al. (2012), drying mixtures of di-acids (malonic, etc.) with chloride salts can cause $\mathrm{HCl}$ to be expelled from the particle, as evidenced by a $30 \%$ loss of $\mathrm{Cl}$ upon reaction. Given that particles in our study were prepared in a similar manner to the Laskin et al. (2012) approach, chloride depletion is likely to occur for the di-valent salts as has been observed for $\mathrm{NaCl} . \mathrm{Cl}$ depletion must be taken into account when estimating the fraction of OxA actually deposited to our salt particles, because we measure the particle diameter after evaporation of $\mathrm{HCl}$ would have occurred. Thus, the final particle volume can be expressed as the sum of the component volume fractions multiplied by their respective molar volumes. Assuming negligible changes to the individual component molar volumes during reaction

$$
\begin{aligned}
& V_{\text {final }}=V_{\text {init }}-V_{\text {react }}+V_{\text {prod }} \\
& \frac{V_{\text {react }}}{V_{\text {init }}}=f_{\text {react }}=\frac{\mathrm{GF}-1}{\left(\beta_{\text {tot }}-1\right)},
\end{aligned}
$$

where $V_{\text {final }}$ is the measured particle volume after OxA deposition and any chemistry that occurs after OxA deposition, $V_{\text {init }}$ is the initial, pure-salt particle volume, $V_{\text {react }}$ is the volume of the pure salt that reacts, $V_{\text {prod }}$ is the volume of the 


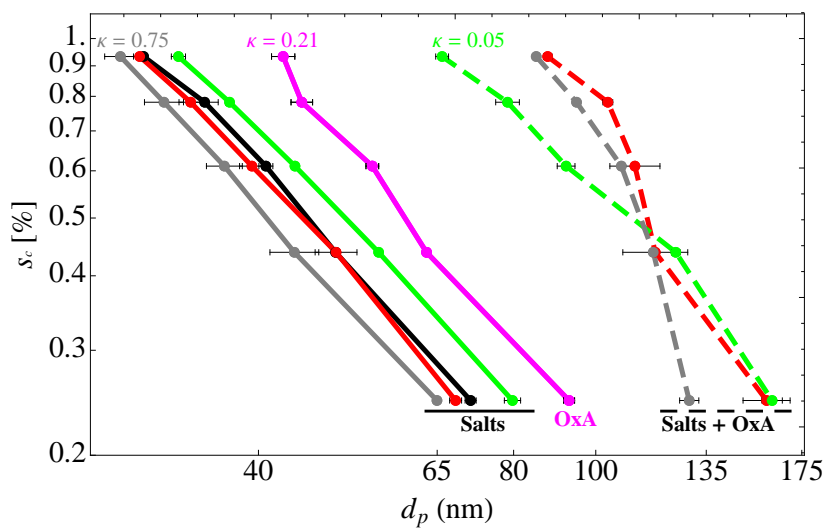

Figure 3. Critical supersaturation, $s_{\mathrm{C}}$, of di-valent salt particles as a function particle diameter. Inorganic salts without $\mathrm{OxA}$ deposition are shown by solid lines: $\mathrm{ZnCl}_{2}$ (gray), $\mathrm{CaCl}_{2}$ (red), $\mathrm{MgCl}_{2}$ (green). The corresponding salts with OxA deposition are dashed lines with the same color. Pure OxA and ammonium sulfate are shown in solid magenta, and black lines, respectively. $\kappa$ values are shown for $\mathrm{ZnCl}_{2}$ (gray), OxA (magenta), and $\mathrm{MgCl}_{2}+\mathrm{OxA}$ (green).

Table 4. Growth factors $\left(\mathrm{V}_{\mathrm{M}+\mathrm{OxA}} / \mathrm{V}_{\mathrm{M}}\right)$ with uncertainties and $\kappa$ values for salts and salt mixtures with OxA deposition. Equations (8) and (9) are used to calculate $\kappa_{\text {calc }}$. Our measured component $\kappa$ values are used for the individual components' $\kappa_{i}$, and a GF of 1.2 was used.

\begin{tabular}{lccc}
\hline Salt aerosol composition & $\mathrm{V}_{\mathrm{M}+\mathrm{OxA}} / \mathrm{V}_{\mathrm{M}}$ & $\kappa_{\text {calc }}$ & $\kappa_{\text {meas }}$ \\
\hline $\mathrm{NaCl}+\mathrm{OxA}$ & $1.23(0.05)$ & 0.81 & 0.68 \\
$8: 1 / \mathrm{NaCl} / \mathrm{MgCl}_{2}+\mathrm{OxA}$ & $1.17(0.05)$ & 0.76 & 0.81 \\
$1: 1 / \mathrm{NaCl} / \mathrm{MgCl}_{2}+\mathrm{OxA}$ & $1.19(0.05)$ & 0.34 & 0.46 \\
$\mathrm{MgCl}_{2}+\mathrm{OxA}$ & $1.18(0.05)$ & 0.3 & 0.05 \\
$\mathrm{CaCl}_{2}+\mathrm{OxA}$ & $1.22(0.05)$ & 0.46 & 0.02 \\
$\mathrm{ZnCl}_{2}+\mathrm{OxA}$ & $1.20(0.05)$ & 0.51 & 0.02 \\
\hline
\end{tabular}

reaction products, $f_{\text {react }}$ is the fraction of oxalic acid reacted, GF is the ratio of the final-to-initial particle diameter, and $\beta_{\text {tot }}$ is the sum of the molar volume of the products divided by molar volume of the pure salt.

The volatility of $\mathrm{HCl}$ gives rise to two limiting cases in which $\mathrm{HCl}$ is treated as completely remaining in the particle and one in which $\mathrm{HCl}$ completely evaporates from the particle. The first case is given by

$\kappa_{\max }=\frac{\left(1-f_{\text {react }}\right) \kappa_{\text {Salt }}+f_{\text {react }}\left(\beta_{\mathrm{M}-\mathrm{Ox}} \kappa_{\mathrm{M}-\mathrm{Ox}}+\beta_{\mathrm{HCl}} \kappa_{\mathrm{HCl}}\right)}{\left(1-f_{\text {react }}\right)+f_{\text {react }}\left(\beta_{\mathrm{M}-\mathrm{Ox}}+\beta_{\mathrm{HCl}}\right)}$

and the second case (complete $\mathrm{HCl}$ evaporation) is given by

$\kappa_{\text {min }}=\frac{\left(1-f_{\text {react }}^{\prime}\right) \kappa_{\text {Salt }}+f_{\text {react }}^{\prime} \beta_{\mathrm{M}-\mathrm{Ox}} \kappa_{\mathrm{M}-\mathrm{Ox}}}{\left(1-f_{\text {react }}^{\prime}\right)+f_{\text {react }}^{\prime} \beta_{\mathrm{M}-\mathrm{Ox}}}$,

where now

$f_{\text {react }}^{\prime}=\frac{(\mathrm{GF}-1)}{\left(\beta_{\mathrm{M}-\mathrm{Ox}}-1\right)}$, and $\beta_{\mathrm{M}-\mathrm{Ox}}$ is the stoichiometry-weighted $\left(n_{\mathrm{M}-\mathrm{Ox}} / n_{\text {salt }}\right)$ ratio of the molar volume of $\mathrm{M}-\mathrm{Ox}$ to the initial pure-salt molar volume.

The assumption that the final particle volume was measured after complete reaction and evaporation of $\mathrm{HCl}$ results in the lowest prediction of the final particle hygroscopicity, because the particle would then contain the maximum possible fraction of insoluble, low-hygroscopicity material. These results, with the measured growth factors after OxA deposition, are listed in Table 4 . The $\kappa_{\text {calc }}$ data in Table 4 are calculated using Eqs. (8) and (9). Growth factors were calculated from particle geometric mean diameters. Some variation in composition (amount of OxA deposition) with size is expected. Three factors suggest that even small particles do not have excessive volumetric fractions of OxA: the linearity of $s_{\mathrm{c}}$ vs. $d_{\mathrm{p}}$ for the mono-valent salt particles, the fact that their hygroscopicities are well below that of pure OxA, and the agreement between their calculated and measured values of $\kappa$. The measured values for $d_{\mathrm{p} 50}$ will only be affected by changes in composition for particles with a diameter near $d_{\mathrm{p} 50}$ and above. Any size-dependent deposition should be biased towards smaller particles, due to larger surface area to volume ratios. The complete reaction is in fact not likely to occur, as the $\mathrm{Cl} / \mathrm{Na}$ ratios for di-acid particles with initial $1: 1$ molar ratio of acid to salt observed by Laskin et al. (2012) never reached zero. While the observed particle hygroscopicities (after OxA deposition) for di-valent salts are low (0.02-0.05), the lowest predicted hygroscopicity is 0.30 for $\mathrm{MgCl}_{2}$. The measured $\kappa$ values are close to the values expected/measured for the pure M-Ox compounds, which have fairly high $\kappa_{\text {intr }}$ that are not realized due to their low solubilities (Sullivan et al., 2009).

The discrepancies between the measured and predicted particle hygroscopicities can be attributed, at least in part, to particle morphologies with inhomogeneous composition, such as a coating. A possible explanation is the formation of an insoluble $\mathrm{M}-\mathrm{Ox}$ coating at the particle surface. This is supported by the similar $\kappa$ values for our salt particles with OxA deposition and the pure M-Ox particles measured by Sullivan et al. (2009). Recently, species present at the particle surface, such as surfactants, have been shown to strongly affect CCN activation (Sareen et al., 2013). Though $\mathrm{M}-\mathrm{Ox}$ compounds may reduce particle surface tensions to as low as $32 \mathrm{mN} \mathrm{m}^{-1}$ (Wu and Nancollas, 1999), we find good agreement between our measured and calculated $\kappa$ values for the $\mathrm{NaCl} / \mathrm{MgCl}_{2}$ mixtures using a surface tension of $72 \mathrm{mN} \mathrm{m}^{-1}$. Thus a coating of the insoluble M-Ox may create a particle that, in terms of CCN activation, behaves as if the particle were composed entirely of the insoluble MOx salt. This potential scenario is also supported by the fact that evolution of $\mathrm{HCl}$ from the particle, which leaves behind insoluble M-Ox, must occur at the particle surface. Finally, a recent study has directly shown the surface enhancement of both $\mathrm{Ca}$ and $\mathrm{Mg}$, suggesting this behavior is not specific to $\mathrm{Mg}$ and may apply to di-valent salts in general (Ault et al., 


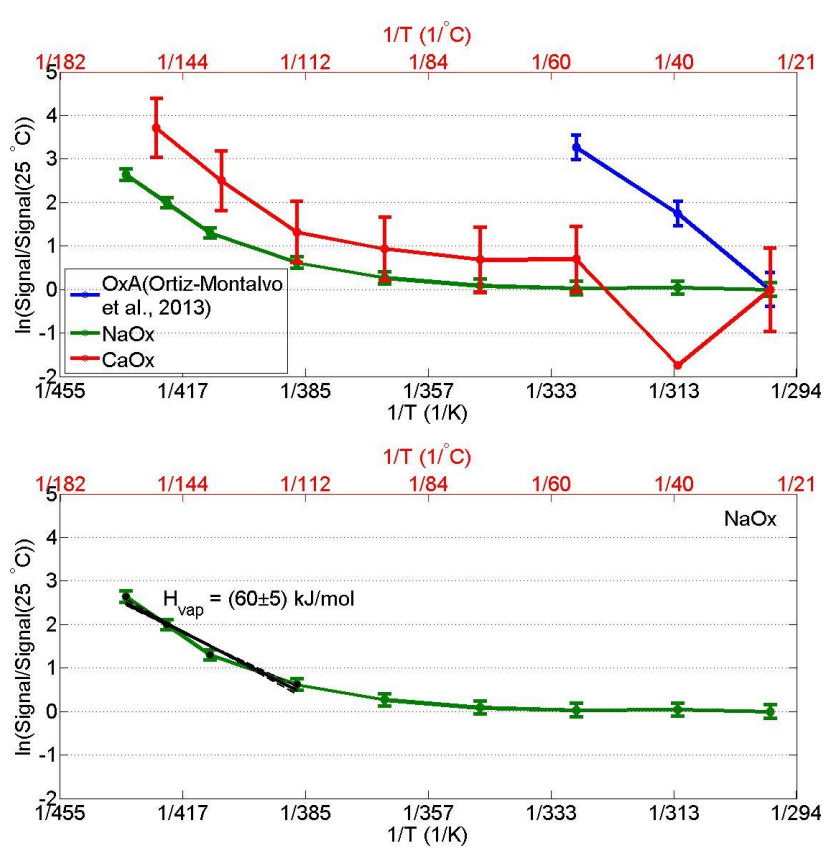

Figure 4. Volatility of $\mathrm{Na}_{2} \mathrm{Ox}$ aerosol with TPD aerosol-CIMS $\left(\mathrm{Na}_{2} \mathrm{Ox}(1)\right)$. The detected oxalate signal when aerosol was heated stepwise from room temperature to $160^{\circ} \mathrm{C}$ as a function of time (minutes from the beginning of the experiment) is illustrated in the figure (black solid line). Also the average oxalate signal at different temperatures is plotted (blue dots). The average background oxalate signal was subtracted from the oxalate signal for further analysis.

2013). Thus, organic coatings, which may lead to formation of insoluble organic salts, especially in regions with di-valent salts, may be prevalent in the atmosphere.

\subsection{Volatility of oxalate salts}

The TPD aerosol-CIMS was calibrated using oxalic acid with well-known $\Delta H_{\text {vap }}\left(83 \mathrm{~kJ} \mathrm{~mol}^{-1}\right.$ at $T=190^{\circ} \mathrm{C}$, Yaws, 2003). In order to determine the $\Delta H_{\mathrm{vap}}$ of oxalic acid aerosol, the average oxalic acid gas phase signal at three different temperatures (mean inlet temperatures $25,39,56{ }^{\circ} \mathrm{C}$ ) was divided by the average signal at room temperature $\left(25^{\circ} \mathrm{C}\right)$ and its logarithm was plotted against the inverse mean inlet temperature (Fig. 5, upper panel). This way the Clausius-Clapeyron equation could be directly applied (Eq. 4) and $\Delta H_{\mathrm{vap}}$ could be estimated from the slope of the calibration curve. In the temperature range of $25-56^{\circ} \mathrm{C}$, we obtained $\Delta H_{\text {vap }}$ of $(85 \pm 12) \mathrm{kJ} \mathrm{mol}^{-1}$ for oxalic acid (Table 1), comparable to the literature value for $\Delta H_{\mathrm{vap}}$ of oxalic acid $\left(95 \mathrm{~kJ} \mathrm{~mol}^{-1}\right)$ (Yaws, 2003). A residence time of one second may not be sufficient to fully equilibrate the aerosol (Riipinen et al., 2010). However, high-particle concentrations and small-particle sizes yield shorter equilibrium times, and in our case particles concentrations are high and particles relatively small, compared to the conditions of $\mathrm{Ri}$ ipinen et al. (2010).

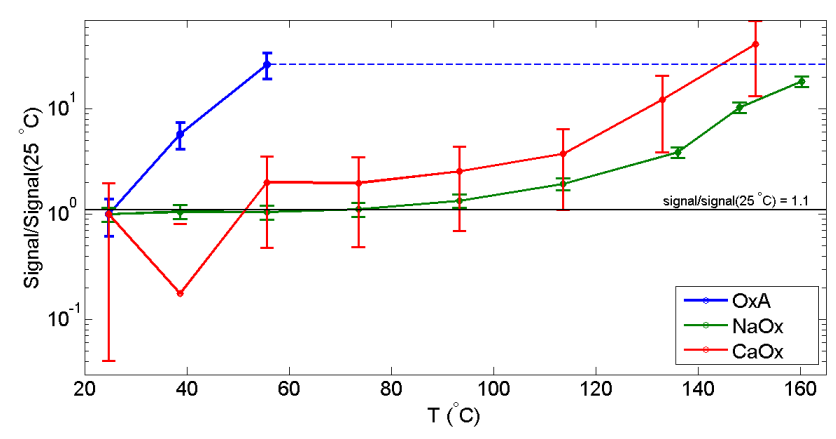

Figure 5. Evaporation of oxalate particles observed with the TPD aerosol-CIMS - natural logarithm of the oxalate signal normalized with the signal at room temperature as a function of inverse mean inlet temperature. Oxalic acid calibration curve (blue), two independent experiments with $\mathrm{Na}_{2} \mathrm{Ox}$ (green) and $\mathrm{CaOx}$ along $\mathrm{CCN}$ experiment (red) are illustrated in the upper panel. Also the approximate onset temperature of evaporation of oxalate salts is marked $\left(75^{\circ} \mathrm{C}\right)$. In the lower panel the estimation of the $\Delta H_{\mathrm{vap}}$ by fitting the data points to Clausius-Clapeyron equation (Eq. 4) above this temperature is shown for $\mathrm{Na}_{2} \mathrm{Ox}$ particles $\left(\mathrm{Na}_{2} \mathrm{Ox}(1)\right)$. Error bars illustrate the standard deviation of the signal from the mean signal.

$\mathrm{CaOx}$ volatility measurements were performed along with $\mathrm{CCN}$ measurements by coupling the TPD aerosol-CIMS with the CFTSGC system (Fig. 1). $\mathrm{Na}_{2} \mathrm{Ox}$ experiments were performed separately. Data for $\mathrm{Na}_{2} \mathrm{Ox}$ are shown in Fig. 4; signal noise was small and the background oxalate level low. A slight, stable signal increase above background signal was observed at room temperature, possibly due to changes in CIMS ionization or residual gas phase oxalate. All other measurements had oxalate signals at the same level as the background (difference around $100 \mathrm{~Hz}$ ) indicating minimal evaporation below $75^{\circ} \mathrm{C}$.

The evaporation curves obtained from the oxalate salt measurements are illustrated in Fig. 5; the calibration curve of oxalic acid is also shown for comparison. The $\mathrm{Na}_{2} \mathrm{Ox}$ particles were generated by atomizing an aqueous solution of sodium oxalate. The $\mathrm{CaOx}$ particles, made by depositing OxA on $\mathrm{CaCl}_{2}$, show the same volatility as pure $\mathrm{CaOx}$. The volatility of the M-Ox salts was very different from that of pure OxA aerosol. A quantitative estimate of the onset evaporation temperature was defined as signal/ $\operatorname{signal}_{25 \mathrm{C}} 1.1$. The resulting onset temperatures were $\mathrm{Na}_{2} \mathrm{Ox}$ : $95^{\circ} \mathrm{C}$ and $\mathrm{CaOx}$ : $115^{\circ} \mathrm{C}$ (Table 4 and Fig. 5). Hence, the oxalate salt particles were significantly less volatile compared to pure oxalic acid aerosol. In other words, the energy needed for the vaporization of oxalates, $\Delta H_{\mathrm{vap}}$, was very large at temperatures below $75^{\circ} \mathrm{C}$, whilst $\Delta H_{\mathrm{vap}}$ was $(85 \pm 12) \mathrm{kJ} \mathrm{mol}^{-1}$ for pure OxA. Similar to our study, high onset temperatures of evaporation have been observed also with other atmospheric organic constituents (Tritscher et al., 2011; Meyer et al., 2009). Tritscher et al. (2011) reported onset evaporation temperature of around $70^{\circ} \mathrm{C}$ for citric acid and both Tritscher et al. (2011) and Meyer et al. (2009) observed onset 
evaporation temperature at around $50^{\circ} \mathrm{C}$ for secondary organic aerosol from $\alpha$-pinene oxidation.

At temperatures above $75^{\circ} \mathrm{C}$, where volatilization of oxalates was observed to be significant, the vapor pressure of oxalates did not follow a strictly exponential dependence with $T$ (Fig. 5), in contrast to OxA aerosol (Riipinen et al., 2006, 2007). It is possible that the thermal decomposition of OxA causes a convolution of two separate signals with slightly different onset temperatures. The complexity of the thermal decomposition was not further studied, because it is not atmospherically relevant. However, we acknowledge that it has some influence on our results at higher temperatures and may be important in thermodenuder experiments. In order to estimate the energy needed for the vaporization of oxalate salts at temperatures $>75^{\circ} \mathrm{C}$, the $\Delta H_{\text {vap }}$ in this temperature range was determined using a linear fit to only the data above $75^{\circ} \mathrm{C}$ (see the lower panel of Fig. 4 for the example linear fit). The average of the obtained $\Delta H_{\text {vap }}$ values for oxalate salts was $(72 \pm 12) \mathrm{kJ} \mathrm{mol}^{-1}$ (Table 1). As discussed above, this value should be taken only as an estimate. TPD aerosol-CIMS results show that, in the case of $\mathrm{CaOx}$ and $\mathrm{Na}_{2} \mathrm{Ox}$, OxA/oxalate is sequestered as very lowvolatility organic salt compounds.

\section{Conclusions and atmospheric implications}

Deposition of OxA to submicron particles containing di-valent salts creates very low hygroscopicity material. Dramatic increases in the $\mathrm{CCN}$ activation diameter, up to $50 \mathrm{~nm}$, for relatively small particle mass fractions of OxA (10-20\%) with di-valent salts (e.g., $\mathrm{CaCl}_{2}$ ) indicate that standard volume additivity rules for hygroscopicity do not apply. High-oxidation state, soluble organic species can strongly decrease hygroscopicity in particles dominated by di-valent salts. Our results are specific to OxA, but strong binding may occur for other DCA. Highly oxidized, soluble organic species, particularly including carboxylic acid groups, can strongly decrease hygroscopicity in particles dominated by di-valent salts. Given current knowledge of the formation mechanisms of OxA and M-Ox salts, surface enrichment of insoluble M-Ox salts is expected, explaining the greater than stoichiometric effects of $\mathrm{M}-\mathrm{Ox}$ salts on particle hygroscopicity. An analogous situation does not occur for particles dominated by mono-valent salts $(\mathrm{NaCl})$, as $\kappa$ values from the standard $\kappa$-calculation for a mixture Eq. (3) agrees with our measurements. A threshold of soluble material is likely met in particles dominated by mono-valent salts, such that overall solubility is high enough to reach ideal behavior. Particles containing oxalate salts, whether pure or formed by OxA deposition to pure salt particles, have very low volatility, indicated by a $75^{\circ} \mathrm{C}$ "onset-temperature" for detection of OxA using TPD aerosol-CIMS. A coating of insoluble material such as $\mathrm{CaOx}$ could result in particles that are hard enough to exhibit bounce on particle impactors and, combined with the low volatility of these salts, may also affect mass transfer properties (evaporation/uptake) of such coated particles. The formation of an insoluble and hard coating of organic salts, supported by the discrepancy between our calculated and observed hygroscopicities, could thus appear in experimental observations (mass transfer limitations and bounce factor) as a glassy, highly viscous state. Because of the potential implications for partitioning/volatility, uptake coefficients, evaporation, and hygroscopicity, the irreversible transformation of volatile, soluble, and high-oxidation-state organic material into non-volatile material may be important in models of organic compound partitioning in the atmosphere.

Edited by: A. Laskin

\section{References}

Altieri, K. E., Seitzinger, S. P., Carlton, A. G., Turpin, B. J., Klein, G. C., and Marshall, A. G.: Oligomers formed through in-cloud methylglyoxal reactions: chemical composition, properties, and mechanisms investigated by ultra-high resolution FTICR mass spectrometry, Atmos. Environ., 42, 1476-1490, 2008.

Ault, A. P., Moffet, R. C., Baltrusaitis, J., Collins, D. B., Ruppel, M. J., Cuadra-Rodriguez, L. A., Zhao, D., Guasco, T. L., Ebben, C. J., Geiger, F. M., Bertram, T. H., Prather, K. A., and Grassian, V. H.: Size-dependent changes in sea spray aerosol composition and properties with different seawater conditions, Environ. Sci. Technol., 47, 5603-5612, 2013.

Backman, J., Virkkula, A., Petäjä, T., Aurela, M., Frey, A., and Hillamo, R.: Impacts of volatilisation on light scattering and filter-based absorption measurements: a case study, Atmos. Meas. Tech., 3, 1205-1216, doi:10.5194/amt-3-1205-2010, 2010.

Barsanti, K. C., McMurry, P. H., and Smith, J. N.: The potential contribution of organic salts to new particle growth, Atmos. Chem. Phys., 9, 2949-2957, doi:10.5194/acp-9-2949-2009, 2009.

Cappa, C. D., Lovejoy, E. R., and Ravishankara, A. R.: Determination of evaporation rates and vapor pressures of very low volatility compounds: a study of the $\mathrm{C} 4-\mathrm{C} 10$ and $\mathrm{C} 12$ dicarboxylic acids, J. Phys. Chem. A., 111, 3099-3109, 2007.

Dinar, E., Anttila, T., and Rudich, Y.: CCN activity and hygroscopic growth of organic aerosols following reactive uptake of ammonia, Environ. Sci. Technol., 42, 793-799, 2008.

Ehn, M., Petäjä, T., Birmili, W., Junninen, H., Aalto, P., and Kulmala, M.: Non-volatile residuals of newly formed atmospheric particles in the boreal forest, Atmos. Chem. Phys., 7, 677-684, doi:10.5194/acp-7-677-2007, 2007.

Ervens, B., Turpin, B. J., and Weber, R. J.: Secondary organic aerosol formation in cloud droplets and aqueous particles (aqSOA): a review of laboratory, field and model studies, Atmos. Chem. Phys., 11, 11069-11102, doi:10.5194/acp-1111069-2011, 2011.

Fu, P., Kawamura, K., Usukura, K., and Miura, K.: Dicarboxylic acids, ketocarboxylic acids and glyoxal in the marine aerosols collected during a round-the-world cruise, Mar. Chem., 148, 22-32, 2013. 
Furukawa, T. and Takahashi, Y.: Oxalate metal complexes in aerosol particles: implications for the hygroscopicity of oxalatecontaining particles, Atmos. Chem. Phys., 11, 4289-4301, doi:10.5194/acp-11-4289-2011, 2011.

Gierlus, K. M., Laskina, O., Abernathy, T. L., and Grassian, V. H.: Laboratory study of the effect of oxalic acid on the cloud condensation nuclei activity of mineral dust aerosol, Atmos. Environ., 46, 125-130, 2012.

Häkkinen, S. A. K., Äijälä, M., Lehtipalo, K., Junninen, H., Backman, J., Virkkula, A., Nieminen, T., Vestenius, M., Hakola, H., Ehn, M., Worsnop, D. R., Kulmala, M., Petäjä, T., and Riipinen, I.: Long-term volatility measurements of submicron atmospheric aerosol in Hyytiälä, Finland, Atmos. Chem. Phys., 12, 10771-10786, doi:10.5194/acp-12-10771-2012, 2012.

Higgins, J., Zhou, X., Liu, R., and Huang, T. T.-S.: Theoretical study of thermal decomposition mechanism of oxalic acid, J. Phys. Chem. A., 101, 2702-2708, 1997.

Kawamura, K., Steinberg, S., and Kaplan, I. R.: Concentrations of monocarboxylic and dicarboxylic acids and aldehydes in southern California wet precipitations: comparison of urban and nonurban samples and compositional changes during scavenging, Atmos. Environ., 30, 1035-1052, 1996.

Kawamura, K., Narukawa, M., Li, S.-M., and Barrie, L. A.: Size distributions of dicarboxylic acids and inorganic ions in atmospheric aerosols collected during polar sunrise in the Canadian high Arctic, J. Geophys. Res.-Atmos., 112, D10307, doi:10.1029/2006JD008244, 2007.

Kokkola, H., Vesterinen, M., Anttila, T., Laaksonen, A., and Lehtinen, K. E. J.: Technical note: Analytical formulae for the critical supersaturations and droplet diameters of CCN containing insoluble material, Atmos. Chem. Phys., 10, 2209-2225, doi:10.5194/acp-10-2209-2010, 2010.

Kulmala, M., Vehkamäki, H., Petäjä, T., Dal Maso, M., Lauri, A., Kerminen, V.-M., Birmili, W., and McMurry, P. H.: Formation and growth rates of ultrafine atmospheric particles: a review of observations, J. Aerosol Sci., 35, 143-176, 2004.

Kumar, P., Nenes, A., and Sokolik, I. N.: Importance of adsorption for CCN activity and hygroscopic properties of mineral dust aerosol, Geophys. Res. Lett., 36, L24804, doi:10.1029/2009GL040827, 2009.

Kundu, S., Kawamura, K., Andreae, T. W., Hoffer, A., and Andreae, M. O.: Molecular distributions of dicarboxylic acids, ketocarboxylic acids and $\alpha$-dicarbonyls in biomass burning aerosols: implications for photochemical production and degradation in smoke layers, Atmos. Chem. Phys., 10, 2209-2225, doi:10.5194/acp-10-2209-2010, 2010.

Lance, S., Medina, J., Smith, J. N., and Nenes, A.: Mapping the operation of the DMT continuous flow CCN counter, Aerosol Sci. Tech., 40, 242-254, 2006.

Laskin, A., Wietsma, T. W., Krueger, B. J., and Grassian, V. H.: Heterogeneous chemistry of individual mineral dust particles with nitric acid: a combined CCSEM/EDX, ESEM, and ICP-MS study, J. Geophys. Res., 110, D10208, doi:10.1029/2004JD005206, 2005.

Laskin, A., Moffet, R. C., Gilles, M. K., Fast, J. D., Zaveri, R. A., Wang, B., Nigge, P., and Shutthanandan, J.: Tropospheric chemistry of internally mixed sea salt and organic particles: surprising reactivity of $\mathrm{NaCl}$ with weak organic acids, J. Geophys. Res., 117, D15302, doi:10.1029/2012JD017743, 2012.
Lee, A. K. Y., Hayden, K. L., Herckes, P., Leaitch, W. R., Liggio, J., Macdonald, A. M., and Abbatt, J. P. D.: Characterization of aerosol and cloud water at a mountain site during WACS 2010: secondary organic aerosol formation through oxidative cloud processing, Atmos. Chem. Phys., 12, 7103-7116, doi:10.5194/acp-12-7103-2012, 2012.

Ma, Q. and He, H.: Synergistic effect in the humidifying process of atmospheric relevant calcium nitrate, calcite and oxalic acid mixtures, Atmos. Environ., 50, 97-102, 2012.

Ma, Q., Liu, Y., and He, H.: The utilization of physisorption analyzer for studying the hygroscopic properties of atmospheric relevant particles, J. Phys. Chem. A, 114, 4232-4237, 2010.

Ma, Q., He, H., and Liu, C.: Hygroscopic properties of oxalic acid and atmospherically relevant oxalates, Atmos. Environ., 69, 281288, 2013.

Martinelango, P. K., Dasgupta, P. K., and Al-Horr, R. S.: Atmospheric production of oxalic acid/oxalate and nitric acid/nitrate in the Tampa Bay airshed: parallel pathways, Atmos. Environ., 41, 4258-4269, 2007.

McNeill, V. F., Wolfe, G. M., and Thornton, J. A.: The oxidation of oleate in submicron aqueous salt aerosols: evidence of a surface process, J. Phys. Chem. A., 111, 1073-1083, 2007.

Meyer, N. K., Duplissy, J., Gysel, M., Metzger, A., Dommen, J., Weingartner, E., Alfarra, M. R., Prevot, A. S. H., Fletcher, C., Good, N., McFiggans, G., Jonsson, A. M., Hallquist, M., Baltensperger, U., and Ristovski, Z. D.: Analysis of the hygroscopic and volatile properties of ammonium sulphate seeded and unseeded SOA particles, Atmos. Chem. Phys., 9, 721-732, doi:10.5194/acp-9-721-2009, 2009.

Myriokefalitakis, S., Tsigaridis, K., Mihalopoulos, N., Sciare, J., Nenes, A., Kawamura, K., Segers, A., and Kanakidou, M.: Incloud oxalate formation in the global troposphere: a 3-D modeling study, Atmos. Chem. Phys., 11, 5761-5782, doi:10.5194/acp11-5761-2011, 2011.

Neusüss, C., Pelzing, M., Plewka, A., and Herrmann, H.: A new analytical approach for size-resolved speciation of organic compounds in atmospheric aerosol particles: methods and first results, J. Geophys. Res.-Atmos., 105, 4513-4527, 2000.

Nenes, A. Charlson, R. J., Facchini, M. C., Kulmala, M., Laaksonen, A., Seinfeld, J. H.: Can Chemical Effects on Cloud Droplet Number Rival the First Indirect Effect?, Geoph. Res. Lett, 29, 1848, doi:10.1029/2002GL01529, 2002.

Ortiz-Montalvo, D. L., Lim, Y. B., Perri, M. J., Seitzinger, S. P., and Turpin, B. J.: Volatility and yield of glycolaldehyde SOA formed through aqueous photochemistry and droplet evaporation, Aerosol Sci. Tech., 46, 1002-1014, 2012.

Pavuluri, C. M., Kawamura, K., and Swaminathan, T.: Watersoluble organic carbon, dicarboxylic acids, ketoacids, and alphadicarbonyls in the tropical Indian aerosols, J. Geophys. Res.Atmos., 115, D11302, doi:10.1029/2009JD012661, 2010.

Petters, M. D. and Kreidenweis, S. M.: A single parameter representation of hygroscopic growth and cloud condensation nucleus activity, Atmos. Chem. Phys., 7, 1961-1971, doi:10.5194/acp-71961-2007, 2007.

Philippin, S., Wiedensohler, A., and Stratmann, F.: Measurements of non-volatile fractions of pollution aerosols with an eight-tube volatility tandem differential mobility analyzer (VTDMA-8), J. Aerosol Sci. Technol., 35, 185-203, 2004. 
Pierce, J. R., Riipinen, I., Kulmala, M., Ehn, M., Petäjä, T., Junninen, H., Worsnop, D. R., and Donahue, N. M.: Quantification of the volatility of secondary organic compounds in ultrafine particles during nucleation events, Atmos. Chem. Phys., 11, 90199036, doi:10.5194/acp-11-9019-2011, 2011.

Pratt, K. A., Twohy, C. H., Murphy, S. M., Moffet, R. C., Heymsfield, A. J., Gaston, C. J., DeMott, P. J., Field, P. R., Henn, T. R., Rogers, D. C., Gilles, M. K., Seinfeld, J. H., and Prather, K. A.: Observation of playa salts as nuclei in orographic wave clouds, J. Geophys. Res.-Atmos., 115, D013606, doi:10.1029/2009JD013606, 2010.

Riipinen, I., Svenningsson, B., Bilde, M., Gaman, A., Lehtinen, K. E. J., and Kulmala, M.: A method for determining thermophysical properties of organic material in aqueous solutions: succinic acid, Atmos. Res., 82, 579-590, 2006.

Riipinen, I., Koponen, I. K., Frank, G. P., Hyvärinen, A.-P., Vanhanen, J., Lihavainen, H., Lehtinen, K. E. J., Bilde, M., and Kulmala, M.: Adipic and malonic acid aqueous solutions: surface tensions and saturation vapor pressures, J. Phys. Chem. A, 111, 12995-13002, 2007.

Riipinen, I., Pierce, J. R., Donahue, N. M., and Pandis, S. N.: Equilibration time scales of oranic aerosol inside thermodenuders: evaporation kinetics vs. thermodynamics, Atmos. Environ., 44, 597-607, 2010.

Riipinen, I., Yli-Juuti, T., Pierce, J. R., Petäjä, T., Worsnop, D. R., Kulmala, M., and Donahue, N. M.: The contribution of organics to atmospheric nanoparticle growth, Nature Geosci., 5, 453-458, 2012.

Rinaldi, M., Decesari, S., Carbone, C., Finessi, E., Fuzzi, S., Ceburnis, D., O’Dowd, C. D., Sciare, J., Burrows, J. P., Vrekoussis, M., Ervens, B., Tsigaridis, K., Facchini, M. C.: Evidence of a natural marine source of oxalic acid and a possible link to glyoxal, J. Geophys. Res., 116, D16204, doi:10.1029/2011JD015659, 2011.

Roberts, G. and Nenes, A.: A continuous-flow streamwise thermalgradient $\mathrm{CCN}$ chamber for atmospheric measurements, Aerosol Sci. Technol., 39, 206-221, 2005.

Saarikoski, S., Mäkelä, T., Hillamo, R., Aalto, P. P., Kerminen, V.-M., and Kulmala, M.: Physico-chemical characterization and mass closure of size-segregated atmospheric aerosols in Hyytiälä, Finland, Boreal Environ. Res., 10, 385-400, 2005.

Saleh, R., Khlystov, A., and Shihadeh, A.: Effect of aerosol generation method on measured saturation pressure and enthalpy of vaporization for dicarboxylic acid aerosols, Aerosol Sci. Technol., 44, 302-307, 2010.

Sareen, N., Schwier, A. N., Lathem, T. L., Nenes, A., and McNeill, V. F.: Surfactants from the gas phase may promote cloud droplet formation, Proc. Natl. Acad. Sci. USA, 110, 2723-2728, 2013

Seinfeld, J., Pandis, s. N.: Atmospheric Chemistry and Physics: From Air Pollution to Climate Change, John Wiley and Sons, New York, 461-464, 2006.

Schwier, A. N., Sareen, N., Lathem, T. L., Nenes, A., and McNeill, V. F.: Ozone oxidation of oleic acid surface films decreases aerosol cloud condensation nuclei activity, J. Geophys. Res., 116, D16202, doi:10.1029/2010JD015520, 2011.

Sempéré, R. and Kawamura, K.: Low molecular weight dicarboxylic acids and related polar compounds in the remote marine rain samples collected from Western Pacific, Atmos. Environ., 30, 1609-1619, 1996.
Smith, J., Barsanti, K., Friedli, H., Ehn, M., Kulmala, M., Collins, D., Scheckman, J., and Williams, B., and McMurry, P.: Observations of aminium salts in atmospheric nanoparticles and possible climatic implications, P. Natl. Acad. Sci. USA, 107, 6634-6639, 2010.

Sorooshian, A., Murphy, S. M., Hersey, S., Gates, H., Padro, L. T., Nenes, A., Brechtel, F. J., Jonsson, H., Flagan, R. C., and Seinfeld, J. H.: Comprehensive airborne characterization of aerosol from a major bovine source, Atmos. Chem. Phys., 8, 5489-5520, doi:10.5194/acp-8-5489-2008, 2008.

Sorooshian, A.,Wang, Z.,Coggon, M. M., Johnson, H. H., and Ervens, B.: Observations of Sharp Oxalate Reductions in Stratocumulus Clouds at Variable Altitudes: Organic Acid and Metal Measurements During the 2011 E-PEACE Campaign, Environ. Sci. Technol., 47, 7747-7756, doi:10.1021/es4012383, 2013.

Sullivan, R. C. and Prather, K. A.: Investigations of the diurnal cycle and mixing state of oxalic acid in individual particles in Asian aerosol outflow, Environ. Sci. Technol., 41, 8062-8069, 2007.

Sullivan, R. C., Moore, M. J. K., Petters, M. D., Kreidenweis, S. M., Roberts, G. C., and Prather, K. A.: Timescale for hygroscopic conversion of calcite mineral particles through heterogeneous reaction with nitric acid, Phys. Chem. Chem. Phys., 11, 78267837, 2009.

Tan, Y., Carlton, A. G., Seitzinger, S. P., and Turpin, B. J.: SOA from methylglyoxal in clouds and wet aerosols: measurement and prediction of key products, Atmos. Environ., 44, 5218-5226, 2010.

Tritscher, T., Dommen, J., DeCarlo, P. F., Gysel, M., Barmet, P. B., Praplan, A. P., Weingartner, E., Prévôt, A. S. H., Riipinen, I., Donahue, N. M., and Baltensperger, U.: Volatility and hygroscopicity of aging secondary organic aerosol in a smog chamber, Atmos. Chem. Phys., 11, 11477-11496, doi:10.5194/acp-1111477-2011, 2011.

Wang, H. B. and Kawamura, K.: Stable carbon isotopic composition of low-molecular-weight dicarboxylic acids and ketoacids in remote marine aerosols, J. Geophys. Res.-Atmos., 111, D07304, doi:10.1029/2005JD006466, 2006.

Wang, H. B., Kawamura, K., and Yamazaki, K.: Water-soluble dicarboxylic acids, ketoacids and dicarbonyls in the atmospheric aerosols over the Southern Ocean and western Pacific Ocean, J. Atmos. Chem., 53, 43-61, 2006.

Warneck, P.: In-cloud chemistry opens pathway to the formation of oxalic acid in the marine atmosphere, Atmos. Environ., 37, 2423-2427, 2003.

Wehner, B., Philippin, S., and Wiedensohler, A.: Design and calibration of a thermodenuder with an improved heating unit to measure the size-dependent volatile fraction of aerosol particles, J. Aerosol Sci., 1087-1093, 2002.

Wehner, B., Petäjä, T., Boy, M., Engler, C., Birmili, W., Tuch, T., Wiedensohler, A., and Kulmala, M.: The contribution of sulfuric acid and non-volatile compounds on the growth of freshly formed atmospheric aerosols, Geophys. Res. Lett., 32, L17810, doi:10.1029/2005GL023827, 2005.

Wu, W. and Nancollas, G. H.: Determination of surface tension from crystallization and dissolution data: a comparison with other methods, Adv. Colloid Interfac., 79, 229-279, 1999.

Yaws, C. L.: Yaws' Handbook of Thermodynamic and Physical Properties of Chemical Compounds, Knovel, available at: http: //www.knovel.com (last access: July 2013), 2003. 